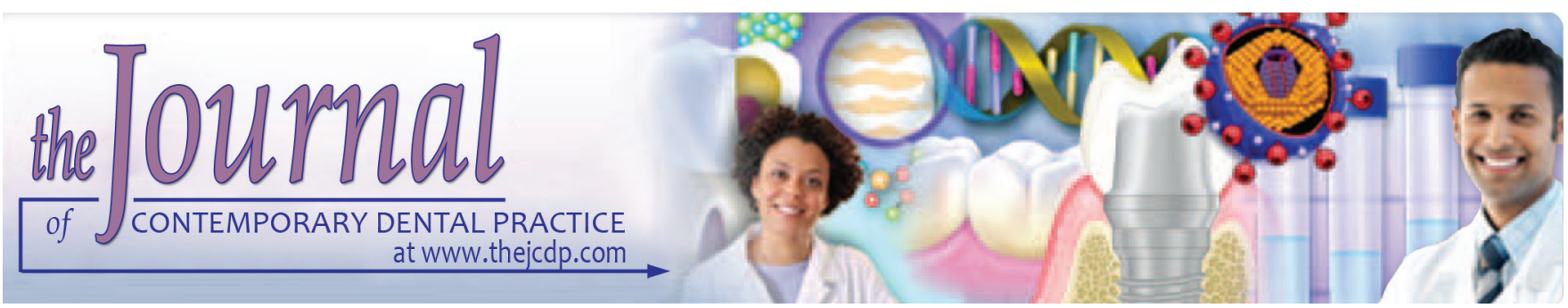

\title{
Influence of Dentin Deproteinization on Bonding Degradation: 1-year Results
}

\author{
${ }^{1}$ César R Pucci, ${ }^{2}$ Natália R Barbosa, ${ }^{3}$ Eduardo Bresciani, ${ }^{4}$ Karen CK Yui, ${ }^{5}$ Maria Filomena RL Huhtala \\ ${ }^{6}$ Daphne C Barcellos, ${ }^{7}$ Carlos RG Torres
}

\begin{abstract}
Introduction: The decalcification protocol of dentin surface with sodium hypochlorite removes the exposed collagen fibrils and could improve the longevity of the bonding interface. This study evaluated the influence of collagen removal with $10 \%$ sodium hypochlorite $(10 \% \mathrm{NaOCl})$ on the longitudinal shear bond strength (SBS) of adhesives to dentin.
\end{abstract}

\begin{abstract}
Materials and methods: Seventy-two extracted human molars were sectioned and the buccal and lingual surfaces were flattened and acid etched with $37 \%$ phosphoric acid for 15 seconds. The specimens were divided into six groups $(n=12$ teeth -24 sections), according to adhesive and collagen removal protocol: group 1: UNO Dentastic; group 2: Prime and Bond NT; group 3: Single Bond; group 4: $10 \% \mathrm{NaOCl}+$ UNO Dentastic; group 5: $10 \% \mathrm{NaOCl}+$ Prime and Bond NT; group 6: $10 \% \mathrm{NaOCl}+$ Single Bond. Composite Z100 buildup was prepared, and the SBS test was assessed after 24 hours and 1 year. Data were submitted to three-way analysis of variance (ANOVA) and Tukey tests $(p<0.05)$.
\end{abstract}

Results: The mean values (MPa) were for 24 hours: G1: $22.45^{\mathrm{B}}$. G2: $7.90^{\mathrm{DE}}$; G3: $12.56^{\mathrm{CD}}$; G4: $19.85^{\mathrm{BC}}$; G5: 33.73A; G6: $20.77^{\mathrm{B}}$; and for 1 year: G1: $2.43^{\mathrm{E}}$; G2: $2.26^{\mathrm{E}}$; G3: $4.3^{\mathrm{DE}}$; G4: $18.79^{\mathrm{BC}}$; G5: $26.49^{A B} ; \mathrm{G} 6: 22.73^{\mathrm{B}}$.

Conclusion: Dentin deproteinization treatment with 10\% $\mathrm{NaOCI}$ influenced the SBS compared with conventional treatment. The negative influence on SBS detected for conventional

\footnotetext{
${ }^{1-5,7}$ Department of Restorative Dentistry, Institute of Science and Technology, Universidade Estadual Paulista - UNESP São Paulo, Brazil

${ }^{6}$ Department of Restorative Dentistry, São José dos Campos School of Dentistry, Universidade Estadual Paulista - UNESP São Paulo, Brazil

Corresponding Author: Carlos RG Torres, Department of Restorative Dentistry, Institute of Science and Technology Universidade Estadual Paulista - UNESP, São Paulo, Brazil Phone: +1239479048, e-mail: carlosrgt@fosjc.unesp.br
}

groups at 1-year interval was not detected for deproteinized groups.

Clinical relevance: The longevity of hybrid layer is critical due to the hydrolysis process at the adhesive interface over time. The use of $10 \% \mathrm{NaOCl}$ deproteinization protocol might improve the longevity of bonding in adhesive restorations.

Keywords: Bond strength, Collagen, Degradation, Dentin, Matrix metalloproteinase, Sodium hypochlorite.

How to cite this article: Pucci CR, Barbosa NR, Bresciani E, Yui KCK, Huhtala MFRL, Barcellos DC, Torres CRG. Influence of Dentin Deproteinization on Bonding Degradation: 1-year Results. J Contemp Dent Pract 2016;17(12):985-989.

\section{Source of support: Nil}

\section{Conflict of interest: None}

\section{INTRODUCTION}

Dental materials and restorative protocols have being modified over the years mainly as a result of technological advances. Direct resin composites are the main focus recently. These advanced techniques might lead to improved longevity and durability of restorations.

Within the adhesive techniques, the longevity of hybrid layer has been widely questioned as a consequence of hydrolysis of the adhesive interface over time. ${ }^{1-3}$ This fact might be a consequence of incomplete infiltration of adhesives and/or exposure of remaining

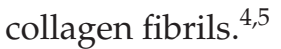

Alternatives are proposed and studied to solve this problem. A method that involves the combination of acid etching of dentin surface and the application of sodium hypochlorite (NaOCI) has been studied. ${ }^{6-9}$ The decalcification protocol of dentin surface led to a more porous dentin, while the application of $\mathrm{NaOCl}$ removes the exposed collagen fibrils. The action of $\mathrm{NaOCI}$ on collagen removal is well determined in the literature due to its known nonspecific proteolytic activity. ${ }^{7}$ 
The whole process results in widened dentinal tubules with no exposed collagen. Dentin surface after this treatment resembles demineralized enamel surface. ${ }^{10}$ This technique is important as the presence of exposed collagen results in a more sensitive bonding procedure, once excessive drying or excessive humidity might compromise the hybrid layer formation, ${ }^{11}$ and also might be related to the weak bonding strength observed over time, probably due to the hydrolysis of the collagen and consequent bonding failure. For these reasons, the dentin treatment with $\mathrm{NaOCl}$ is believed to improve the longevity of the bonding interface as this interface is based on mineral content and on little or no organic component. ${ }^{8}$

There are data to support this procedure at a short period of evaluation, ${ }^{7,12,13}$ while almost no data are available to determine if this approach might bring advantages in comparison to the conventional methodology over periods of time. Moreover, reports in the literature show influence on bond strength according to the type of the adhesive used in association with the deproteinization protocol. $^{6}$

Therefore, this laboratory study aimed to evaluate in vitro the influence of collagen removal with $10 \% \mathrm{NaOCI}$ on the bond strength to dentin as a function of storage time and type of adhesive system.

The tested hypotheses were (1) that no influence on shear bond strength (SBS) would be detected between the use of deproteinization technique and the conventional method, (2) no influence on time would be detected, and (3) the adhesives would behave similarly in relation to bond strength.

\section{MATERIALS AND METHODS}

Seventy-two extracted human molars were cleaned and stored in distilled water, and kept at $-18^{\circ} \mathrm{C}$ prior to use. The materials used are presented in Table 1.

Table 1: Materials used in the present study and their respective composition

\begin{tabular}{|c|c|}
\hline Name & Composition \\
\hline $\begin{array}{l}\text { DenTASTIC UNO } \\
\text { (Pulpdent) }\end{array}$ & $\begin{array}{l}\text { Pyromellitic dianhydride with glycerol } \\
\text { dimethacrylate (PMGDM) primer with } \\
\text { hydrophilic resin and acetone as solvent }\end{array}$ \\
\hline $\begin{array}{l}\text { Prime and Bond NT } \\
\text { (Dentsply Caulk) }\end{array}$ & $\begin{array}{l}\text { Acetone, dimethacrylate, trimethacrylate, } \\
\text { dipentacriterol pentacrylate phosphate }\end{array}$ \\
\hline $\begin{array}{l}\text { Adper Single Bond } \\
(3 \mathrm{M} \text { ESPE) }\end{array}$ & $\begin{array}{l}\text { HEMA, Bis-GMA, dimethacrylate, } \\
\text { copolymers of polyacrylic and poly-itaconic } \\
\text { acids, water, ethanol, photoinitiators }\end{array}$ \\
\hline $\begin{array}{l}10 \% \text { sodium } \\
\text { hypochlorite }\end{array}$ & $10 \% \mathrm{NaOCl}$ solution \\
\hline Z-100 (3M ESPE) & TEGDMA, Bis-GMA, silica, zirconia \\
\hline $\begin{array}{l}35 \% \text { phosphoric } \\
\text { acid gel }\end{array}$ & $35 \%$ phosphoric acid gel \\
\hline
\end{tabular}

The roots were removed using a low-speed cutting machine (Labcut 1010 - Extec Corp., Enfield, CT, USA). Crowns were sectioned along the mesiodistal axial plane (LabCut 1010) into buccal and lingual sections. Teeth sections were embedded in acrylic resin, and enamel was ground using 80-grit silicon carbide abrasive paper (3M ESPE, St. Paul, MN, USA), adapted to a plaster cutting machine under water cooling to avoid overwarming. The remaining dentin thickness was standardized to $2 \mathrm{~mm}( \pm 0.1 \mathrm{~mm})$ with the aid of a digital caliper. The smear layer of the dentin surfaces was standardized using the sequence of 320,400, and 600 grit abrasive papers under water cooling in a polishing machine (Struers DP-I0, São Paulo, Brazil).

The dentin bonding area was standardized in $3 \mathrm{~mm}$ diameter by means of a Teflon adhesive tape presenting a circular opening.

The specimens were divided into six groups, each consisting of 12 teeth ( 24 sections), according to the adhesive system and dentin treatment (Table 2). Dentin was etched for 15 seconds with $35 \%$ phosphoric acid prior to adhesive application. The adhesive procedures were performed in accordance with the manufacturer's specifications. The $\mathrm{NaOCI}$ solution was applied in groups 4 and 6 after the acid etching step and prior to adhesive application. After 60 seconds, the $\mathrm{NaOCl}$ solution was rinsed off and dentin surface was kept humid for adhesive application.

Resin composite buildup area and volume $(3 \mathrm{~mm}$ in diameter and $4 \mathrm{~mm}$ high) were standardized using a prefabricated metallic device orifice over the dentintreated surface. The resin composite was inserted using the incremental technique and light cured with an XL 3000 (3M ESPE) at $500 \mathrm{~mW} / \mathrm{cm}^{2}$, assessed by means of a radiometer. The specimens were light cured for an additional 40 seconds after removing the metallic device.

Table 2: Division of groups according to adhesive system used and deproteinization protocol

\begin{tabular}{|c|c|c|}
\hline Groups & Adhesive system & $\begin{array}{l}\text { Deproteinization } \\
\text { with } 10 \% \mathrm{NaOCl}\end{array}$ \\
\hline G1 & $\begin{array}{l}\text { DenTASTIC UNO adhesive } \\
\text { (Pulpdent, Watertown, } \\
\text { Massachusetts, USA) }\end{array}$ & Not performed \\
\hline G2 & $\begin{array}{l}\text { Prime and Bond NT (Dentsply/ } \\
\text { Caulk, Milford, Delaware, USA) }\end{array}$ & Not performed \\
\hline G3 & $\begin{array}{l}\text { Adper Single Bond (3M ESPE, } \\
\text { St. Paul, Minnesota, USA) }\end{array}$ & Not performed \\
\hline G4 & $\begin{array}{l}\text { DenTASTIC UNO adhesive } \\
\text { (Pulpdent, Watertown, } \\
\text { Massachusetts, USA) }\end{array}$ & $\begin{array}{l}\text { Applied for } \\
60 \text { seconds }\end{array}$ \\
\hline G5 & $\begin{array}{l}\text { Prime and Bond NT (Dentsply/ } \\
\text { Caulk, Milford, Delaware, USA) }\end{array}$ & $\begin{array}{l}\text { Applied for } \\
60 \text { seconds }\end{array}$ \\
\hline G6 & $\begin{array}{l}\text { Adper Single Bond ( } 3 \text { M ESPE, } \\
\text { St. Paul, Minnesota, USA) }\end{array}$ & $\begin{array}{l}\text { Applied for } \\
60 \text { seconds }\end{array}$ \\
\hline
\end{tabular}


Influence of Dentin Deproteinization on Bonding Degradation: 1-year Results

Each group was randomly subdivided into half for the 24-hour and 1-year shear bond evaluation. The specimens were immersed in distilled water at room temperature and stored at $37^{\circ} \mathrm{C}$ for 24 hours or 1 year. Distilled water was changed weekly for the 1-year interval groups.

The specimens were submitted to SBS test in a universal test machine (DL-1 000, EMIC, São José dos Pinhais, $\mathrm{PR}$, Brazil) at $1 \mathrm{~mm} / \mathrm{min}$ crosshead speed, under a knifeedge load, in accordance with ISO TR 11405 standards. The SBS value was assessed in MPa.

The fracture specimens were submitted to optic microscopy analysis (Stemi 2000C, Carl Zeiss, Thomwood, NY, USA) and classified into four types of fracture: Cohesive fracture in resin composite, predominantly (equal or more than $75 \%$ ) within resin composite (type 1), cohesive fracture in dentin, predominantly (equal or more than $75 \%$ ) within dentin (type 2), adhesive fracture, predominantly at the dentin/adhesive or adhesive/resin interface (type 3 ), and mixed fracture, a combination of cohesive and adhesive fractures with no predominance (type 4).

Data were submitted to three-way analysis of variance (ANOVA; factors: Type of adhesive, storage interval, and deproteinization protocol) and Tukey's test, both at 5\% level of significance.

\section{RESULTS}

According to analysis of variance (ANOVA), the type of adhesive did not influence the SBS results $(\mathrm{p}=0.1958)$, while both the use of the deproteinization protocol and the storage interval did $(\mathrm{p}<0.001)$.

The obtained mean values for the shear bond testing and standard deviations are listed in Table 3. The homogeneous groups determined by Tukey's test are presented in Table 4.

Group 5 (Prime and Bond with 10\% NaOCl, 24 hours water storage) showed the highest SBS mean values.

Table 3: Mean SBS values and standard deviation of tested groups

\begin{tabular}{lllll}
\hline Groups & $10 \% \mathrm{NaOCl}$ & Period & $\begin{array}{l}\text { Mean value } \\
(\mathrm{MPa})\end{array}$ & $\begin{array}{l}\text { Standard } \\
\text { deviation }\end{array}$ \\
\hline G1 & Without & 24 hours & 22.45 & 8.64 \\
G1 & Without & 1 year & 2.432 & 0.80 \\
G4 & With & 24 hours & 19.85 & 8.91 \\
G4 & With & 1 year & 18.80 & 1.61 \\
G2 & Without & 24 hours & 7.90 & 4.55 \\
G2 & Without & 1 year & 2.26 & 1.890 \\
G5 & With & 24 hours & 33.73 & 14.31 \\
G5 & With & 1 year & 26.49 & 4.23 \\
G3 & Without & 24 hours & 12.56 & 6.54 \\
G3 & Without & 1 year & 4.30 & 3.21 \\
G6 & With & 24 hours & 20.77 & 10.16 \\
G6 & With & 1 year & 22.73 & 3.48 \\
\hline
\end{tabular}

Table 4: Homogeneous groups determined by Tukey's test. Groups accompanied by same letters presented no significant differences

\begin{tabular}{lllllll}
\hline Groups & Period & Mean & & \multicolumn{3}{c}{ Homogeneous groups } \\
\hline G5 & 24 hours & 33.73 & A & & & \\
G5 & 1 year & 26.49 & A & B & & \\
G6 & 1 year & 22.73 & B & & \\
G1 & 24 hours & 22.45 & B & & \\
G6 & 24 hours & 20.77 & B & C & & \\
G4 & 24 hours & 19.85 & B & C & & \\
G4 & 1 year & 18.80 & B & C & & \\
G3 & 24 hours & 12.56 & & C & D & \\
G2 & 24 hours & 7.90 & & & D & E \\
G3 & 1 year & 4.30 & & & D & E \\
G1 & 1 year & 2.43 & & & & E \\
G2 & 1 year & 2.26 & & & & E \\
\hline
\end{tabular}

Table 5: Type of fractures detected for each group

\begin{tabular}{llllll}
\hline & & \multicolumn{4}{c}{ Type of fracture } \\
\cline { 3 - 6 } Group & Storage interval & I & II & III & IV \\
\hline G1 & 24 hours & 0 & 0 & 8 & 4 \\
G2 & 24 hours & 0 & 0 & 12 & 0 \\
G3 & 24 hours & 0 & 0 & 9 & 3 \\
G4 & 24 hours & 0 & 0 & 8 & 4 \\
G5 & 24 hours & 0 & 0 & 7 & 5 \\
G6 & 24 hours & 0 & 0 & 6 & 6 \\
G1 & 1 year & 0 & 0 & 7 & 5 \\
G2 & 1 year & 0 & 0 & 5 & 7 \\
G3 & 1 year & 0 & 0 & 3 & 9 \\
G4 & 1 year & 0 & 0 & 6 & 6 \\
G5 & 1 year & 0 & 0 & 1 & 11 \\
G6 & 1 year & 0 & 0 & 3 & 9 \\
\hline
\end{tabular}

Groups receiving no deproteinization protocol with storage interval of 1 year (G1, G2, and G3 at 1 year) presented the worst SBS values. On the contrary, groups receiving the deproteinization protocol with the same interval (1 year) presented higher SBS values.

The type of fracture detected under microscopy for each group is listed in Table 5. The adhesive and mixed fractures were the only detected types of fracture.

\section{DISCUSSION}

The first and second hypotheses were rejected as differences were detected. The third hypothesis, related to adhesive type, was accepted as no influence of adhesive type on the SBS to deproteinized dentin was observed.

The longevity of hybrid layer within esthetic restorations is critical as this layer undergoes hydrolysis over time due to the presence of collagen fibrils ${ }^{14}$ and also the presence of hydrophilic resin monomers. The longterm adhesion to dentin is still questionable ${ }^{15}$ thus the importance of improvements and developing/testing new procedures is required. The use of dentin deproteinization has been reported and the literature on the 
bond strength of collagen-depleted dentin is conflicting. While some reports show no negative influence of the deproteinization process on SBS, ${ }^{6,8,13}$ others do. ${ }^{7,12}$ This divergence might be attributed to differences on methodology of several studies, mainly regarding the protocol of application of adhesive systems or the concentration of $\mathrm{NaOCl}$ solution used. ${ }^{16}$ Our results detected positive influence of deproteinization protocol on the SBS over time in comparison to nondeproteinized dentin groups. While no statistical differences on SBS were detected over time for the deproteinization process, the nondeproteinized dentin groups resulted in statistical SBS decrease over time.

The presence of residual reactive free radicals in deproteinized dentin, ${ }^{6,17}$ which present oxidizing potential and possible influence on the polymerization of monomers of dental adhesives, ${ }^{15,18}$ might have played a role in the previously reported data, especially when using extended $\mathrm{NaOCl}$ application protocols. The residues from $\mathrm{NaOCI}$ treatment, mainly oxidant components, might not have been present in our study, as the deproteinization treatment positively influenced the SBS results compared with nondeproteinized groups. The use of the wet bonding technique in the present study might also have played a role on the SBS of deproteinized groups, as this technique is reported not to influence the adhesion to deproteinized dentin. ${ }^{19}$

The application time is also reported to negatively influence the bond strength to deproteinized dentin. ${ }^{20}$ The longer the $\mathrm{NaOCl}$ application time, the smaller the bond strength. Our results, although using long $\mathrm{NaOCl}$ treatment protocol, were not negatively influenced by the deproteinization in both evaluated periods, contradicting previously reported studies. ${ }^{7,18}$

Another important factor present in our study is the variable storage time. Over time, it is known that the hydrolysis of hybrid layer takes place, ${ }^{21}$ as possibly detected in Table 1 with groups not receiving the deproteinization protocol. On the contrary, no influence over time on SBS for groups receiving the deproteinization protocol was detected (Table 1). ${ }^{12}$ This fact might be explained by the lack/absence of hybrid layer formed in dentin receiving deproteinization protocols. This possible lack of conventional hybrid layer positively influenced the results of deproteinized dentin over time, once bond strength is not influenced by collagen hydrolysis, as collagen is not present. Deproteinized dentin surface is highly mineralized and rough, resembling enamel..$^{10}$ The positive influence of the tested protocol might also result from facilitated monomer diffusion. ${ }^{22}$ Results after 6 months of water storage revealed smaller SBS values in comparison to immediate results. ${ }^{12}$ The layer formed in deproteinized dentin is frequently named reverse hybrid layer.
The influence of dentin depth and type of adhesive has also been studied. Dentin depth has been reported not to influence the results of SBS when deproteinization treatment was performed. ${ }^{6,8}$ Although not assessed, dentin specimens' depth was standardized in our study in order to avoid any bias.

It also seems that the influence of deproteinization on dentin SBS is material dependent. ${ }^{6}$ The use of acetone over deproteinized dentin is reported not to influence the SBS. ${ }^{6}$ On the contrary, the use of self-etching adhesives is reported to negatively influence the bond strength when associated with deproteinization protocol and over time. ${ }^{13}$ The concentration of solvents of adhesive systems is also reported to influence the bond strength to deproteinized dentin. ${ }^{19}$ The influence of monomer and composition of dental adhesives on bond strength of deproteinized dentin is not fully understood, thus more studies are required to understand the process. Our study is in agreement with these observations as no influence of adhesive type was detected.

The type of fractures detected after 24 hours and 1 year of assessment was similar. No cohesive fracture, either in dentin or in resin, was detected. The use of $\mathrm{NaOCl}$ solution did not influence the type of fracture as all fractures were at the interface or mixed fractures.

\section{CONCLUSION}

It was concluded that the dentin deproteinization treatment with $10 \% \mathrm{NaOCl}$ influenced the SBS compared with conventional treatment. The decrease in bond strength after 1 year was not significant for groups receiving the deproteinization protocol, a fact not detected within the other groups in which SBS drop was significant, except for the Prime and Bond groups.

\section{REFERENCES}

1. Tay FR, Hashimoto M, Pashley DH, Peters MC, Lai SC, Yiu CK, Cheong C. Aging affects two modes of nanoleakage expression in bonded dentin. J Dent Res 2003 Jul;82(7):537-541.

2. Sano H, Yoshiyama M, EbisuS, Burrow MF, Takatsu T, Ciucchi B, Carvalho R, Pashley DH. Comparative SEM and TEM observations of nanoleakage within the hybrid layer. Oper Dent 1995 Jul-Aug;20(4):160-167.

3. Pashley DH, Tay FR, Imazato S. How to increase the durability of resin-dentin bonds. Compend Contin Educ Dent 2011 Sep;32(7):60-64, 66.

4. Sano H, Shono T, Takatsu T, Hosoda H. Microporous dentin zone beneath resin-impregnated layer. Oper Dent 1994 Mar-Apr;19(2):59-64.

5. Pashley DH, Carvalho RM. Dentine permeability and dentine adhesion. J Dent 1997 Sep;25(5):355-372.

6. Aguilera FS, Osorio R, Osorio E, Moura P, Toledano M. Bonding efficacy of an acetone/based etch-and-rinse adhesive after dentin deproteinization. Med Oral Patol Oral Cir Bucal 2012 Jul;17(4):e649-654. 
7. Perdigão J, Lopes M, Geraldeli S, Lopes GC, García-Godoy F. Effect of a sodium hypochlorite gel on dentin bonding. Dent Mater 2000 Sep;16(5):311-323.

8. Toledano M, Perdigão J, Osorio E, Osorio R. Influence of $\mathrm{NaOCl}$ deproteinization on shear bond strength in function of dentin depth. Am J Dent 2002 Aug;15(4):252-255.

9. Perdigão J, Thompson JY, Toledano M, Osorio R. An ultramorphological characterization of collagen-depleted etched dentin. Am J Dent 1999 Oct;12(5):250-255.

10. Sakae T, Mishima H, Kozawa Y. Changes in bovine dentin mineral with sodium hypochlorite treatment. J Dent Res 1988 Sep;67(9):1229-1234.

11. Tay FR, Gwinnett AJ, Wei SH. The overwet phenomenon: an optical, micromorphological study of surface moisture in the acid-conditioned, resin-dentin interface. Am J Dent 1996 Feb;9(1):43-48.

12. Silva GO, Barcellos DC, Pucci CR, Borges AB, Torres CR. Longitudinal bond strength evaluation using the deproteinized dentin technique. Gen Dent 2009 Jul-Aug;57(4):328-333; quiz 334-5.

13. Abo T, Asmussen E, Uno S, Tagami J. Short- and long-term in vitro study of the bonding of eight commercial adhesives to normal and deproteinized dentin. Acta Odontol Scand 2006 Aug;64(4):237-243.

14. Spencer P, Ye Q, Park J, Misra A, Bohaty BS, Singh V, Parthasarathy R, Sene F, Gonçalves S, Laurence J. Durable bonds at the adjesive/dentin interface: an impossible mission or simply a moving target? Braz Dent Sci 2012 Jan-Mar;15(1):4-18.
15. Ruyter IE. The chemistry of adhesive agents. Oper Dent Suppl 1992;Suppl 5:32-43.

16. Munksgaard EC. Wet or dry, normal or deproteinized dentin surfaces as substrate for dentin adhesives. Acta Odontol Scand 2002 Jan;60(1):60-64.

17. Yiu CK, Garcia-Godoy F, Tay FR, Pashley DH, Imazato S, King NM, Lai SC. A nanoleakage perspective on bonding to oxidized dentin. J Dent Res 2002 Sep;81(9):628-632.

18. Lai SC, Mak YF, Cheung GS, Osorio R, Toledano M, Carvalho RM, Tay FR, Pashley DH. Reversal of compromised bonding to oxidized etched dentin. J Dent Res 2001 Oct;80(10):1919-1924.

19. Faria ESAL, Araujo JE, Rocha GP, Oliveira AD, de Moraes RR. Solvent content and dentin bond strengths using water-wet, ethanol-wet and deproteinization bonding techniques. Acta Odontol Scand 2013 May-Jul;71(3-4):710-715.

20. Kunawarote S, Nakajima M, Shida K, Kitasako Y, Foxton RM, Tagami J. Effect of dentin pretreatment with mild acidic $\mathrm{HOCl}$ solution on microtensile bond strength and surface $\mathrm{pH}$. J Dent 2010 Mar;38(3):261-268.

21. De Munck J, Van Landuyt K, Peumans M, Poitevin A, Lambrechts P, Braem M, Van Meerbeek B. A critical review of the durability of adhesion to tooth tissue: methods and results. J Dent Res 2005 Feb;84(2):118-132.

22. Wege HA, Aguilar JA, Rodriguez-Valverde MA, Toledano M, Osorio R, Cabrerizo-Vilchez MA. Dynamic contact angle and spreading rate measurements for the characterization of the effect of dentin surface treatments. J Colloid Interf Sci 2003 Jul;263(1):162-169. 